\title{
Comparison of Conventional and Modern Controllers for a Gas Turbine Power Plant
}

\author{
Yılmaz Arıkuşu (D), Nevra Bayhan (D), Hasan Tiryaki (D) \\ Department of Electrical and Electronics Engineering, Istanbul University-Cerrahpaşa, Istanbul, Turkey
}

Cite this article as: Arıkuşu Y, Bayhan N, Tiryaki H. Comparison of Conventional and Modern Controllers for a Gas Turbine Power Plant. Electrica, $2019 ; 19(2): 146-157$.

\section{ABSTRACT}

Nowadays, many thermal power plants are established for the generation of electrical energy. In this study, the design of a Gas Turbine Power Plant is analyzed in Ambarl, Turkey. Then, conventional and modern control techniques are applied for comparison. These controllers are conventional proportional and integral (PI), particle swarm optimization based proportional-integral (PSO-PI) and fuzzy gain scheduled proportional-integral (FGPI). The results show that, the performance of the proposed FGPI is better than the conventional controllers on settling time and overshoot of power outputs.

Keywords: Thermal Power Plant, FGPI, Fuzzy Controller, PI Controller, Particle Swarm Optimization

\section{Corresponding Author: \\ Yılmaz Arıkuşu}

E-mail:

arikusuyilmaz@gmail.com

Received: 10.06 .2019

Accepted: 12.06 .2019

(c) Copyright 2019 by Electrica Available online at

http://electrica.istanbul.edu.tr

DOI: 10.26650/electrica.2019.19032

Content of this journal is licensed under a Creative Commons Attribution-NonCommercial 4.0

International License.

\section{Introduction}

The generation of electrical energy has gained more importance with the increasing demand and environmental awareness in recent years. Nowadays, a considerable part of the energy generation is provided by fossil fuel based thermal power plants. However, the coal combustion gases can harm the environment and human health. One of the main reasons for these situations, is the change in the parameters of the gas turbine during the generation of energy. The simplest evidence of this is the contamination of the boiler and heating pipe surfaces of the thermal power plant that has been occured throughout the years by coal-burning [1].

Combined cycle power plants (CCPP) has been proposed in [2]. In this study, the effects of inlet fogging and optimization on performance is considered by energy analysis. Moreover, it is indicated that one of the best methods to reduce $\mathrm{CO}_{2}$ emissions is decreasing the energy losses.

In addition to [1], the control systems play important role due to natural expectations of consumers and the necessity of generation of electricity. Thus, the importance of the control systems in energy generations are rised drastically as shown in [3]. In recent study, energy optimization is performed by using varies optimization algorithm to minimize the $\mathrm{CO}_{2}$ values and raise the efficiency of the power plant in [4]. In this study, NSGA-II (Non-dominated Sort Genetic Algorithm-II) is applied to get the final solutions in the multi-objective optimization of the CCPP. In [5], Genetic Algorithm and Artificial Bee Colony Optimization are applied for environmental economic load dispatch. Thus, it provides a great advantage for cost reduction and $N O_{x}$ emission as a result.

Modern optimization and control techniques are applied with the optimized set values and their effects on the active power-frequency control are analyzed in Ambarl, Turkey in [6]. In the same study, 6 different controller types are performed; PI, PSO-PI, Artificial Bee Colony based Proportional-Integral (ABC-PI), Proportional-Integral-Derivative (PID), Particle Swarm Optimization based Proportional Integral-Derivative (PSO-PID) and Artificial Bee Colony based Proportional-Integral -Derivative (ABC-PID). According to the mentioned work, PID controller 
optimized with artificial bee colony optimization gives better results when compared to the other controllers. Furthermore, the model of Ankara-Çayırhan Thermal Power Plant is also considered [7]. Two different controller types are performed in the mentioned study which are PSO-PID and FGPI for their effects on overshoot and settling time. If minimum settling time is required, PSO-PID must be employed. On the other hand, FGPI can be utilized if minimum overshoot and soft adaptation are desired.

In [8], linear matrix inequalities are solved by Genetic Algorithm and Particle Swarm Optimization for adaptive sliding mode controller design is presented. The unstable situation in the gas turbine is overcame by this method. In addition to these, Particle Swarm Optimization-based controller is applied to the thermal power plant in [9]. The reason for this is to prove that, the proposed controller provides a better settling time response than the conventional controllers. Furthermore, a gas turbine engine is regulated with the PSO-based PI controller to illustrate the optimal control solution.

A fractional order fuzzy-PID (fuzzy-FOPID) controller is suggested for cycle power plant ( CPP) with dynamic particle swarm optimization system [10]. Fuzzy-FOPID offers the best possible results when compared to the other methods in this study.

In our paper, firstly the model of Gas Turbine Power Plant in Ambarlı, Turkey is obtained and the block diagrams of each module are illustrated with different controllers that are conventional PI, PSO-PI and FGPI. Moreover, the responses of the system with respect to these controllers are compared. The two significant parameters for comparison are overshoot and settling time. It is observed that, although PI controller has no overshoot, the settling time is greater than the other controllers. If cost reduction is considered, this can be taken into account. Contrary, FGPI controller has much better settling time when compared to former. Nevertheless, the proposed study showed that modern control techniques are much more proper than the conventional controllers. The parameters of the controllers are determined by the classical methods. Furthermore, FGPI also increases both the performance and service life of the power plant therefore, employment of the these methods is a necessity for the operation of modern power plants.

\section{Basic Mathematical Model for Gas Turbine}

One of most popular power generations systems is the natural gas power plant. Here, air is compressed, burned and enlarged in the turbine to obtain power. Operation principle of gas turbine power plants is as follows: the natural gas is passed through the regulation and measuring station (RMS) and reduced to the operation pressure. It is stored or transmitted to the plant for immediate use with a continuous gas cycle. The natural gas passed through the filter station in the power plant field is transferred to the combustion chambers via the emergency stop and regulation valves. The common shaft includes compressor and turbine. In the model, we used two large silo type combustion chambers with a hybrid burner. Combustion technology is of great importance in terms of environmental legislation. The waste NOx generated after combustion, must be below the threshold value $(300 \mathrm{mg} / \mathrm{Nm} 3)$. The required air in the combustion chamber is obtained by open loop and used with air filters.

The whole system consists of a gas turbine compressor, combustion chamber and turbine. In some cases, it only refers as the turbine. Figure 1 shows the simplified model of the gas turbine. When atmospheric air enters the compressor it is compressed and send to the combustion chamber. In the combustion chamber, high-pressure hot gas is burned by fuel injection. Power is obtained by expanding the turbine. Then, a large portion of the power provided by the turbine is used to run the compressor and a small portion is used in auxiliary tools, the remaining portion is the net power obtained from the plant. Simplified gas turbines should provide air standard requirements.

Simplified model,

- The fluid is air, it is assumed as the ideal gas throughout the cycle

- The combustion process is not taken into account, it is assumed that heat is supplied from outside at constant pressure

- The turbine exhaust and compressor suction operations are neglected. The fluid goes out of the turbine under constant pressure is feedbacked into the compressor.

Whereas the power plant is considered as a closed system where the parameters of the system such as turbine and combustion chamber are open loop components. Cycles which depend on assumptions of air standards are defined as ideal air cycles. Besides these assumptions, models have other assumptions such as some of the state changes are considered to be reversible to obtain approximate results.

Figure 1 shows the P-V and T-s graphs of the Brayton cycle, a simple gas turbine. Heat exchanges are made at constant pressure and compression and expansion processes are isotropic. In this graph, the T-s diagram refers to the gas turbine cycle. From the place where entropy increases, it is seen that the constant pressures are separate. What this means is that, the power provided by the compressor is greater than that provided by the turbine. Otherwise, the target cannot be obtained from the turbine.

Turbine power, compressor power, net power and yield are obtained by applying the first law of thermodynamics to the gas turbine cycle. Thus, it is seen that the yield is a function of the pressure ratio. The yield does not depend on the maximum temperature, the change in specific temperatures depends on the yield temperature.

The Brayton and Carnot cycles with the same temperature range and the same entropy changes are shown on the same 
T-s diagram in Figure 2. From the graph, it can be seen that the Brayton cycle consists of small Carnot cycles. Thus, the yield of the Carnot cycle is higher than that of Brayton. The simplified gas turbine is based on the Carnot cycle $[6,11]$.

\section{Speed Regulator}

The turbine power is constantly changes by the variation of the load. The imbalance between the generated power and con- sumed powers is considered as a change in the speed of the turbine. If the load is variable, the generation must be variable to keep the frequency constant. This is done through the by the speed regulator. The speed regulator adjusts the amount of gas to the combustion chamber of the gas turbine. This cycle is a closed cycle which continues until the power and speed error are zero. The amount of gas is controlled by the control valve in the gas turbine. The stop valve is a valve that is connected in front of the control valve and is for protection purposes.
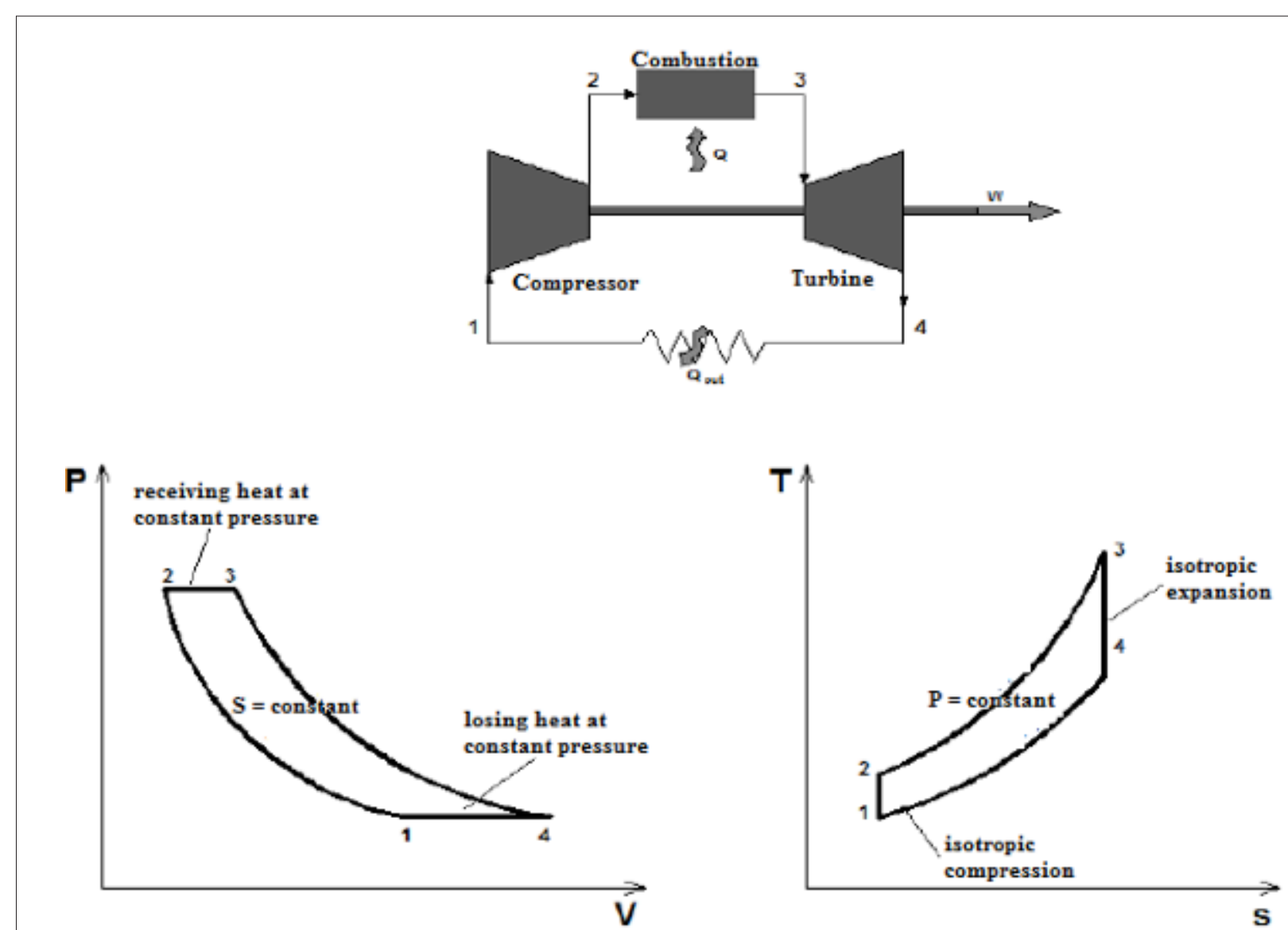

Figure 1. A Simple Gas Turbine Cycle
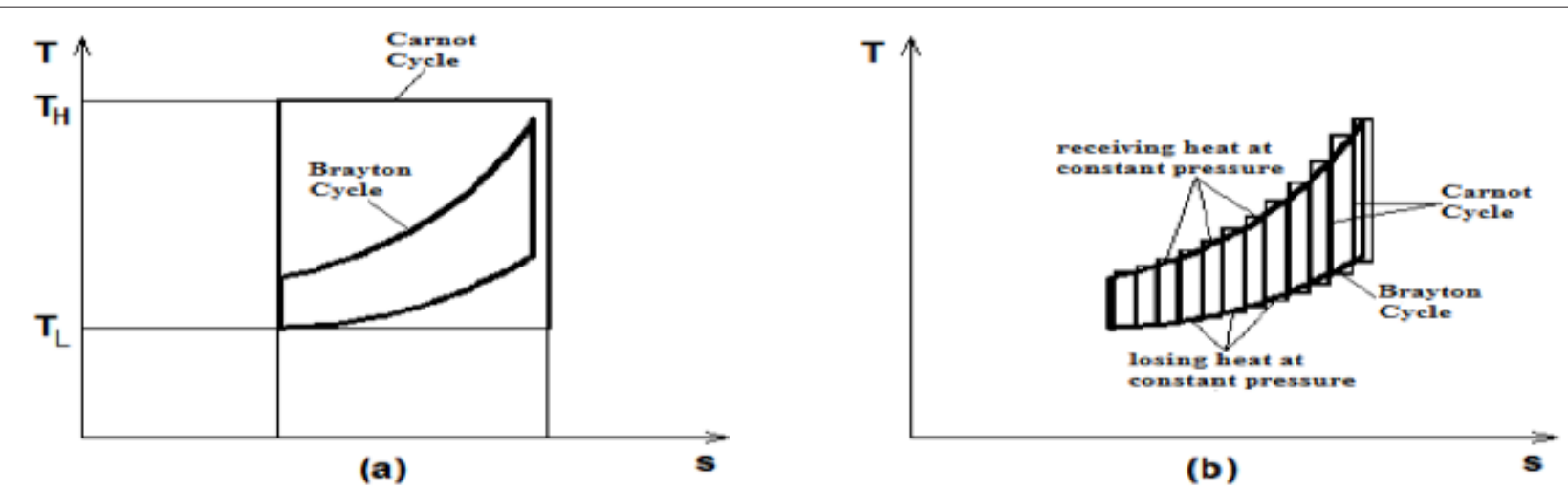

Figure 2. Comparison between Brayton and Carnot Cycles Efficiencies 
Block diagram of a simplified Gas Turbine is illustrated in Figure 3 where speed regulator is first order system.

where

$\mathrm{Kd}$ : Speer regulator gain

X: Speed regulator primary time (delay) constant

Y: Speed regulator secondary time (delay) constant

a: Burner gain constant

b: Burner time (delay) constant

T_Y: Combustion chamber time (delay) constant

T_GT: Time (delay) constant depends on turbine dynamic characteristics

Calculated values for related parameters are given in Table 1.

\section{Basic Mathematical Model for the Generator}

Generators in power systems are generally considered to be large masses with two opposite moments in Figure 4.

The mechanical moment $\left(T_{m}\right)$ is produced in the turbine and this force has an effect that increases the speed of rotation. In contrast, the electrical moment $\left(T_{e}\right)$ generated by the load causes the speed to be reduced. This happens at a constant speed $\left(\omega=\omega_{0}\right)$ when the two moments are equal. The electrical load increases $T_{e}>T_{m}$ and the generator slows down. In this

Table 1. Simplified Gas Turbine Parameter Values[6]

\begin{tabular}{lccccccc}
\hline Parameter & $\mathbf{K}_{\mathbf{d}}$ & $\mathbf{X}$ & $\mathbf{Y}$ & $\mathbf{a}$ & $\mathbf{b}$ & $\mathbf{T} \_\mathbf{Y}$ & $\mathbf{T} \_\mathbf{G T}$ \\
\hline Value & 1 & 0.65 & 0.1 & 1 & 0.05 & 0.4 & 0.1 \\
\hline
\end{tabular}

case, the generator is accelerated again. Otherwise, the generator is decelerated. In power systems, all these operations are repeated continuously, because the load is not stable. Generator equations are as follows,

$T_{T}=l a$

$M=I \omega$

$P_{T}=\omega T_{T}=\omega / a=M a$

where I is current per phase, $a$ is field flux, $\omega$ is angular speed, M is momentum and $T_{T}$ is total torque.

Initially, it is a single rotating machine and the speed is $\omega_{0}$ and $\delta_{0}$ is called as phase angle. Due to the increase of the requested load or mechanical and electrical deterioration, the values $T_{m}$ and $T_{e}$ will change. Speed of the machine in case of acceleration is obtained in the following term.

$\omega=\omega_{0}+a t$

and

$$
\Delta \delta=\int\left(\omega_{0}+\alpha t\right) d t-\int \omega_{0} d t=\omega_{0} t+\frac{1}{2} \alpha t^{2}-\omega_{0} t=\frac{1}{2} \alpha t^{2}
$$

$\Delta \omega$ (frequency deviation) can be identified as,

$$
\Delta \omega=\alpha t=\left(\frac{d}{d t}\right) \Delta \delta
$$

The relation between phase angle deviation, speed deviation and net acceleration moment is given in equation (7).

$T_{T}=I \alpha=I\left(\frac{d}{d t}\right)(\Delta \omega)=I\left(\frac{d^{2}}{d t^{2}}\right)(\Delta \delta)$

Thus, we find the net power

$P_{T}=P_{m}-P_{e}$
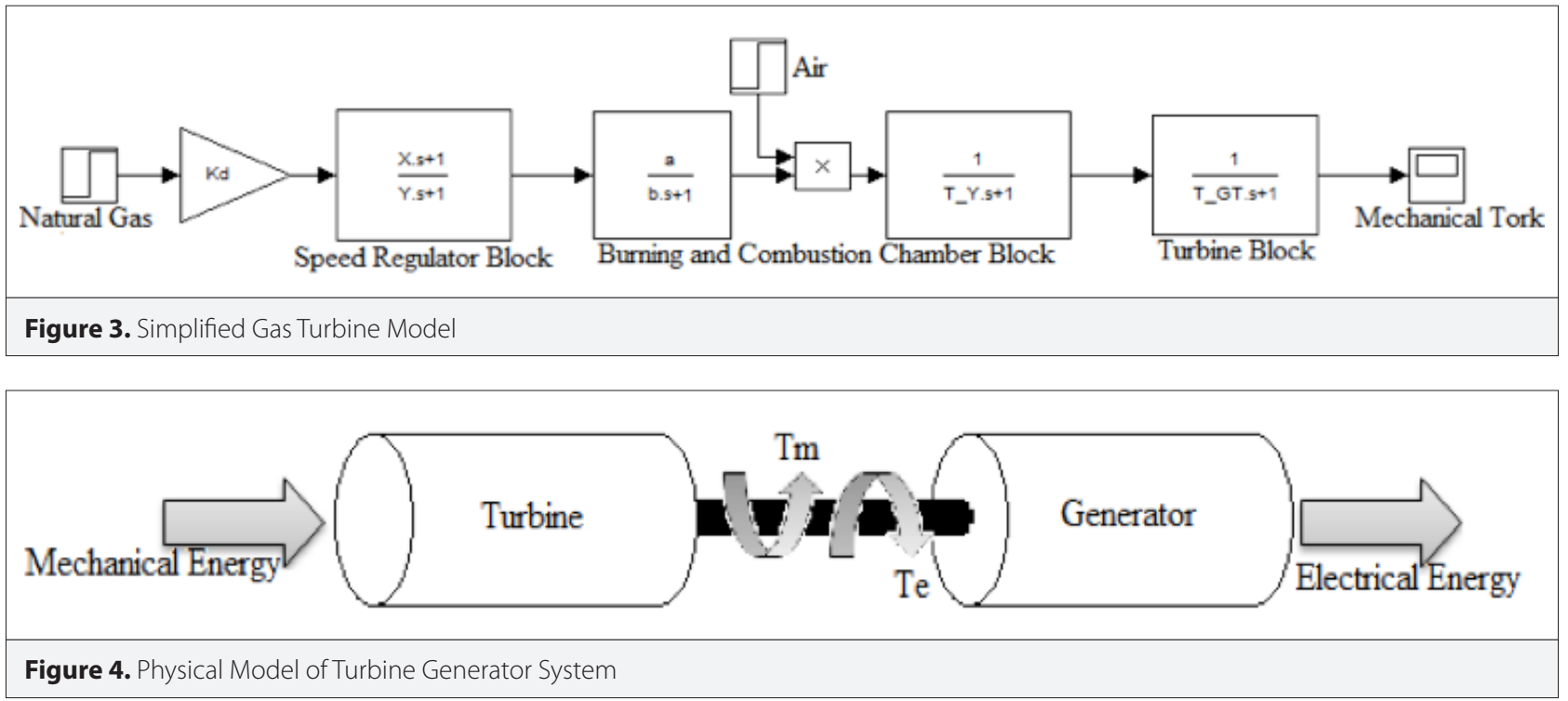
The connection between net power frequency variation is given in equation (9).

$P_{T}=\omega_{0} I\left(\frac{d \Delta \omega_{0}}{d t}\right)=M \frac{d \Delta \omega_{0}}{d t}$

If equality (9) is written in Laplace form

$\omega_{0}=\frac{1}{M s} P_{T}=\frac{1}{M s}\left(P_{m}-P_{e}\right)$
The block diagram of the system obtained from theseequations is shown in Figure 5.

The relation between frequency change $\Delta \omega$ and load change $\Delta P_{L}$ is given in equation (11).
$\Delta P_{e}=\Delta P_{L}+\Delta P_{D} \rightarrow \Delta P_{L}=D \Delta \omega \rightarrow D=\frac{\Delta P_{L}}{\Delta \omega}$

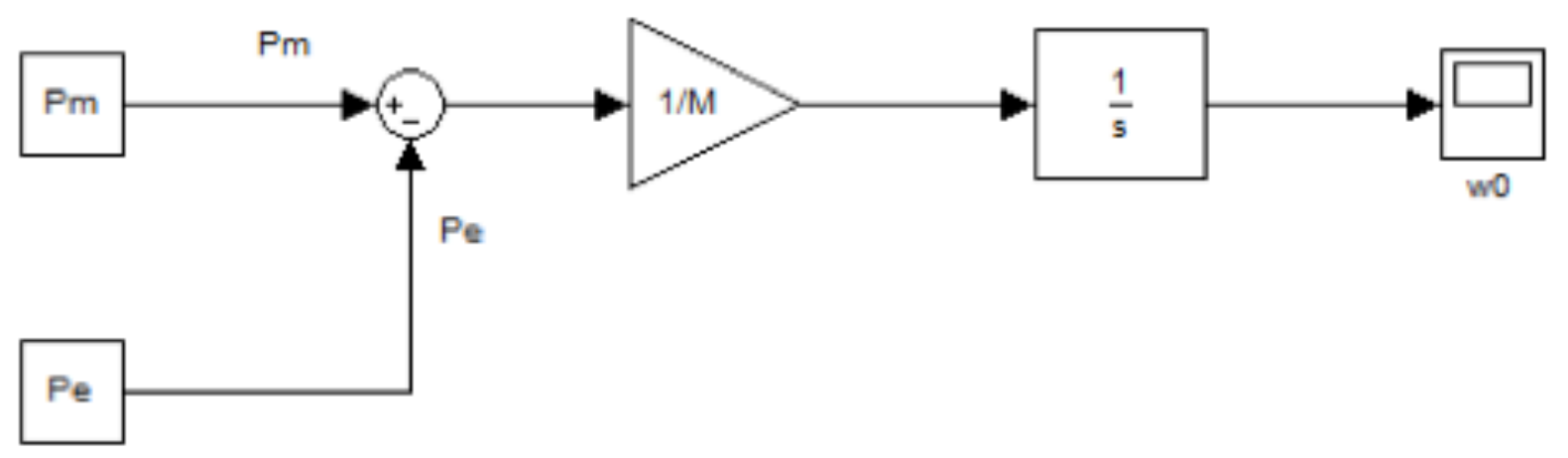

Figure 5. Simplified Block Diagram of Turbine-Generator System

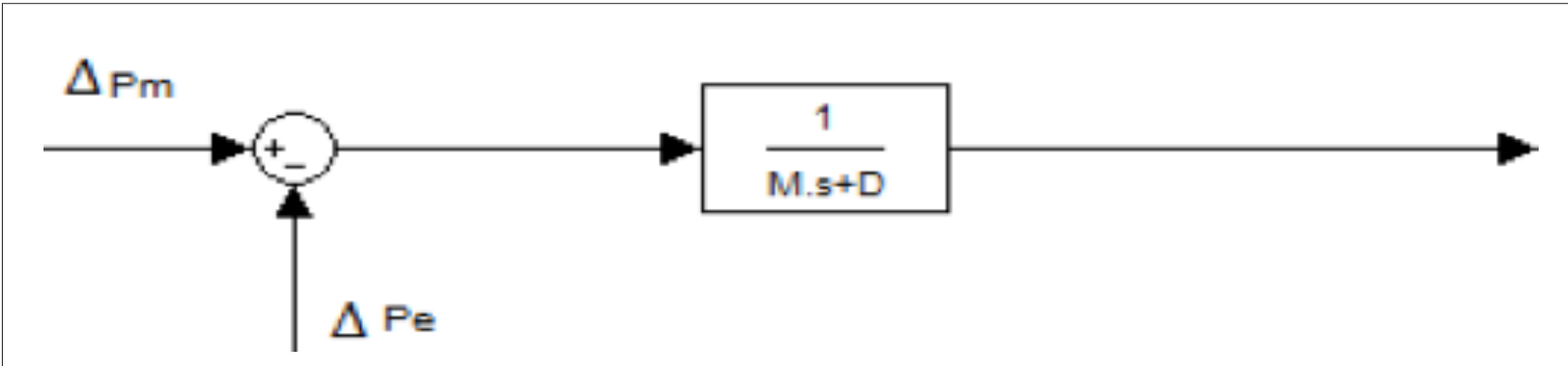

Figure 6. Block Diagram of the Rotating Mass and Load
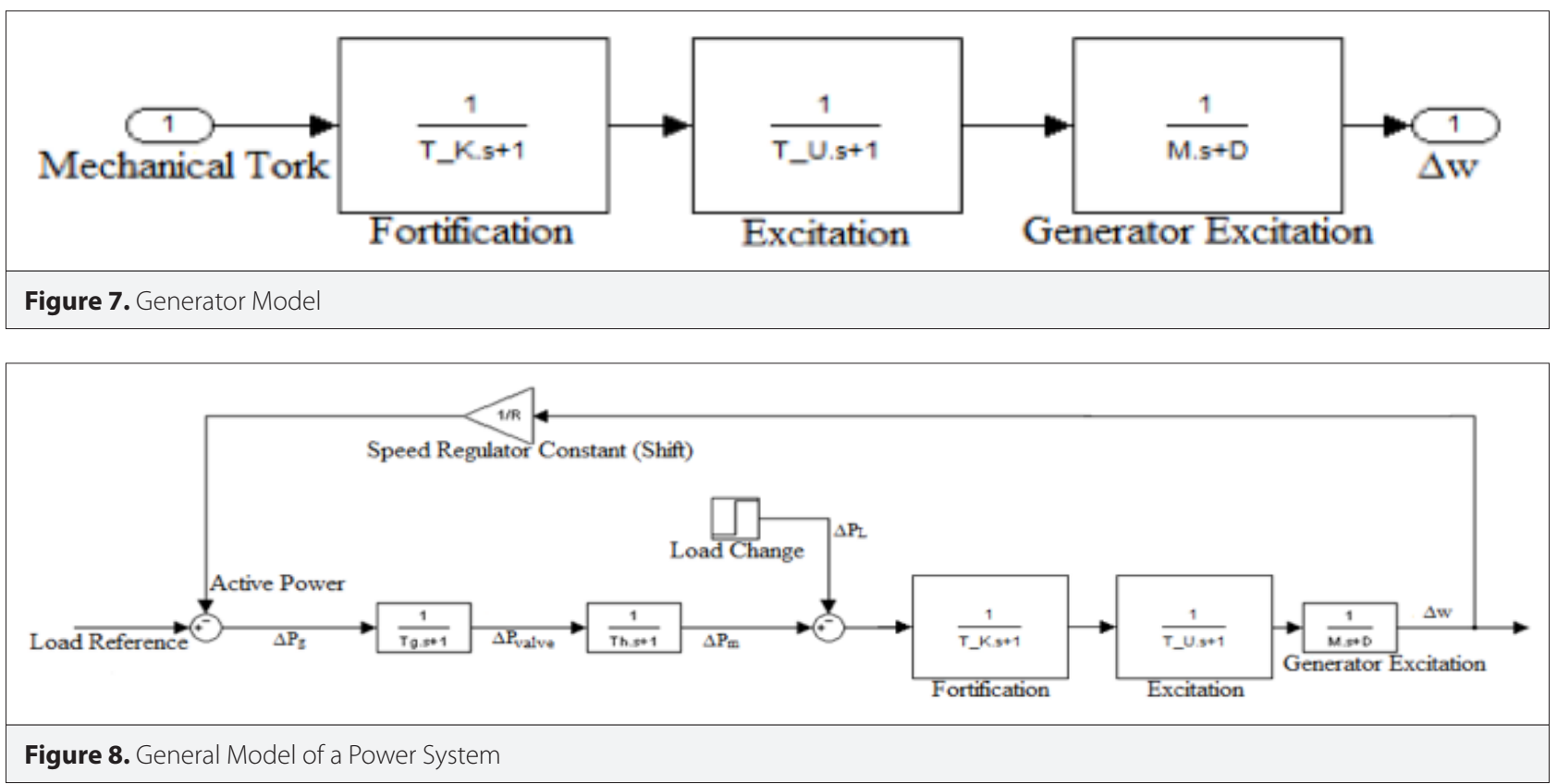
$D$ is the damping constant. It is the percentage of change in frequency which is about $1-2 \%$ for the load change. For example, if there is a frequency change of $1 \%$ in a load variation of $1 \%$, the damping ratio is obtained from equation (11). The damping factor is $D=1 / 1=1$. The load damping model is shown in Figure 6.

If the automatic voltage regulator (AVR) fortification and excitation blocks are added, the diagram becomes as the following in Figure 7.

An overview of the power system can be examined as in Figure 8.

The $R$ value in the figure determines the speed output power characteristics of the production unit. $\mathrm{R}$ called as speed regulation constant or shift, shown in equation (12).

$\mathrm{R}=\frac{\Delta \omega}{P_{j n}}=\frac{\Delta f}{P_{j n}}=\frac{f_{2}-f_{1}}{P_{j n}}$

where

$\mathrm{P}_{\mathrm{jn}}$ : Nominal active power of the generator unit (MW)

$\mathrm{f}_{2}$ : No load frequency $(\mathrm{Hz})$

$\mathrm{f}_{1}$ : Frequency in nominal load $(\mathrm{Hz})$

R: Speed regulation constant or slip (Hz/MW)

$\Delta \omega:$ Speed

$\Delta \mathrm{P}:$ frequency distortion

Thus, the speed regulation constant is added to the system to obtain a simplified generator model in Figure 9.

where

T_K: $\quad$ Fortification time (delay) constant (seconds)

T_U: $\quad$ Excitation time (delay) constant (seconds)

Table 2. Simplified Generator Parameter Values[6]

\begin{tabular}{lccccc}
\hline Parameter & T_K & T_U & M & D & R \\
\hline Value & 0,25 & 1 & 0,1 & 1 & 1 \\
\hline
\end{tabular}

M: $\quad$ Generator time (delay) constant (seconds)

D: Damping Factor

R: $\quad$ Speed regulation constant or slip (Hz/MW)

All values of parameters are given in Table 2 .

Table 2: Simplified Generator Parameter Values[6]

\section{Controller Methods}

The reason for using control systems, the reference value given in the system dynamics parameter changes and depending on the situation defined at the desired level to perform the control criteria.

\section{Conventional PI Controller}

The system's response curve method is employed to obtain the best result of the control system in Figure 10 [12].

In a system, there are parameters that affect the settling time of the controller. These are the time constant $T_{s^{\prime}}$ dead time delay $T_{d}$ and system gain. The parameters of the PI controllers according to the system's response curve method are shown in Table 3.

PI controller structure is given in equations $[13,14]$.

$K(s)=K_{p} e(t)+K_{i} \int_{0}^{t} e(t) d t$

Table 3. PI Controller's Parameter Values[6]

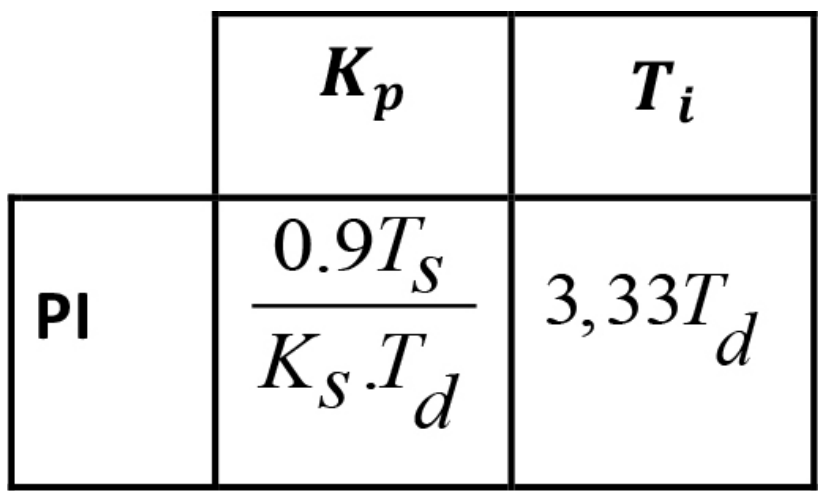

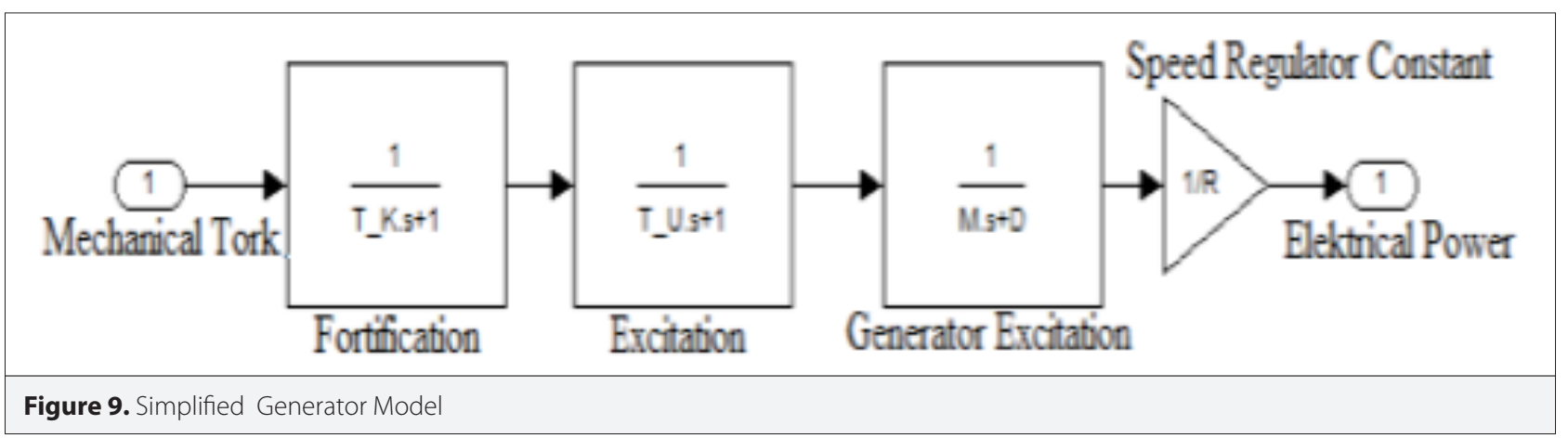


$\frac{K_{p}}{T_{i}}=K_{i}$

$K_{p}$ is proportional gain coefficient, $K_{i}$ integral gain coefficient, $e(t)$ is the time error.

PI controller values were obtained by using equation (14) for Gas Turbine.

Result of PI controller parameters are calculated as $K_{p}=0.680$ and $K_{i}=0.6$.

\section{Particle Swarm Optimization Based PI Controller}

In literature, particle swarm optimization (PSO) is proposed to find the best results of numerical problems based on the social behavior of bird flocks. In the PSO, each individual or particle travels through the solution space that is identified. Each individual keeps the places it ever visited and best one among them in its mind as well as all the other members of the flock. Then, the total best individual experiences are taken into account and compared to each other in order to reach the global best.

Each individual seeks a solution in the $X Y$ coordinate plane in a two-dimensional solution space. The speed of the individual is defined by $v_{x}$ and $v_{y}$ (moving along the $X$ and $Y$ axes). Each individual keeps its best value as the best "pbest" value in memory. In addition, each individual keeps the information of the best value, gbest information and pbest information. The position and velocities of each individual are shown in equation (15) and equation (16) as the following term in [13].

$\vartheta_{\mathrm{i}}^{\mathrm{k}+1}=\vartheta_{\mathrm{i}}^{\mathrm{k}}+\mathrm{c}_{1} \operatorname{rand}_{1} \cdot\left(\mathrm{p}_{\text {best }_{\mathrm{i}}}-\mathrm{s}_{\mathrm{i}}^{\mathrm{k}}\right)+\mathrm{c}_{2} \operatorname{rand}_{2} \cdot\left(\mathrm{g}_{\text {best }}-\mathrm{s}_{\mathrm{i}}^{\mathrm{k}}\right)$

$\mathrm{s}_{\mathrm{i}}^{\mathrm{k}+1}=\mathrm{s}_{\mathrm{i}}^{\mathrm{k}}+\vartheta_{\mathrm{i}}^{\mathrm{k}+1}$

The PSO shows the movement of the search point in a two-dimensional solution space. $s^{k}$ and ve $s^{k+1}$ shows the current and new individual locations. Moreover, $\vartheta^{k}$ and $\vartheta^{k^{+1}}$ shows current and new speeds respectively.

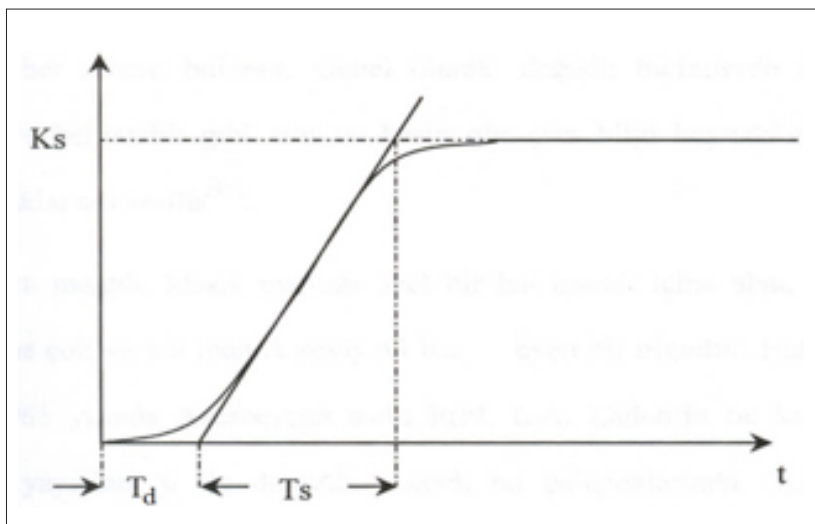

Figure 10. Response Curve $\vartheta_{\text {pbest }}$ and $\vartheta_{\text {gbest }}, p_{\text {best }}$ and $g_{\text {best }}$ shows the speeds according to their location. Changes in the individual position of these vectors are shown in Figure 11.

The equation (17), (18) which are kept within a certain limit for the damping and oscillation at certain points of the speed, are shown [14].

$V^{\max }=\left(x^{\max }-x^{\min }\right)(\% 10-\% 20)$

$V^{\min }=-V^{\max }$

It is kept between certain values by using the coefficients of the particles

$\vartheta_{\mathrm{i}}^{\mathrm{k}+1}=\mathrm{X} \cdot\left[\vartheta_{\mathrm{i}}^{\mathrm{k}}+\mathrm{c}_{1} \operatorname{rand}_{1} \cdot\left(\mathrm{p}_{\text {best }}-\mathrm{s}_{\mathrm{i}}^{\mathrm{k}}\right)+\mathrm{c}_{2} \operatorname{rand}_{2} \cdot\left(\mathrm{g}_{\text {best }}-\mathrm{s}_{\mathrm{i}}^{\mathrm{k}}\right)\right]$

$X$ is the constraint coefficient that is given in equation (20).

$\mathrm{X}=\frac{2}{\left|2-\varphi-\sqrt{\varphi^{2}-4 \varphi}\right|}, \varphi=\mathrm{c}_{1}+\mathrm{c}_{2}, \varphi>4$

Through the restriction coefficient, individuals will be collected at a single point in the future. Figure 12 shows the particle swarm optimization algorithm scheme [15].

The optimization software is designed to approach the fitness function which indeed is the sum of absolute values of errors to zero.

In the simulation stage, the speed ranges of the individuals are determined as in equation (17) and equation (18). In order to compensate local and global search performances, the $X$ coefficient of equation (19) and equation (20) is used. For simulation, the number of individuals is 5 and the number of iterations is 20. The sum of the absolute values of the error function is used as the target function. The goal of optimization is to find the most appropriate PI gain values. Figure 13 shows a block diagram of the control of particle swarming

As the result of optimization $K_{p}$ and $K_{i}$ are found 0.5880 , 0.7156 .

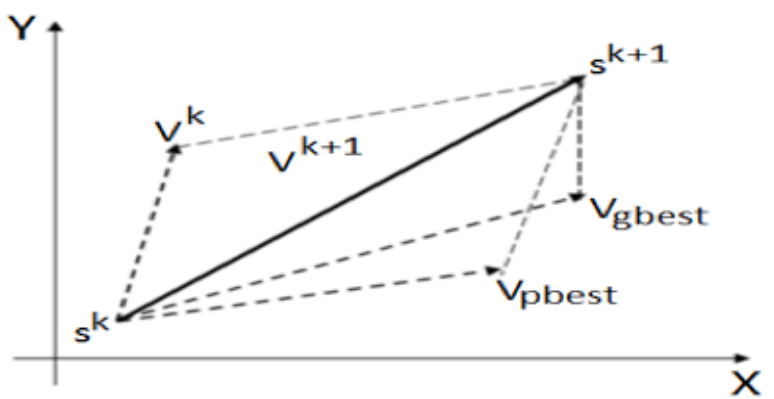

Figure 11. Particles Movement 


\section{The Proposed FGPI Controller}

An alternative to Boolean algebra, fuzzy logic system is more suitable for human thought. In particular, it provides great convenience in complex and uncertain control systems.

Fuzzy gain scheduling proportional and integral (FGPI) control generated in the system for each entry and output. Seven membership function has been created. The membership functions created are expressed as follows; NB (Negative Large), NO (Negative Medium), NK (Negative Small), S (Zero), PK (Positive Small), PO (Positive Medium), PB (Positive Large). All membership are chosen as trimf (triangle membership function) because of the more sensitive control range. The value ranges of

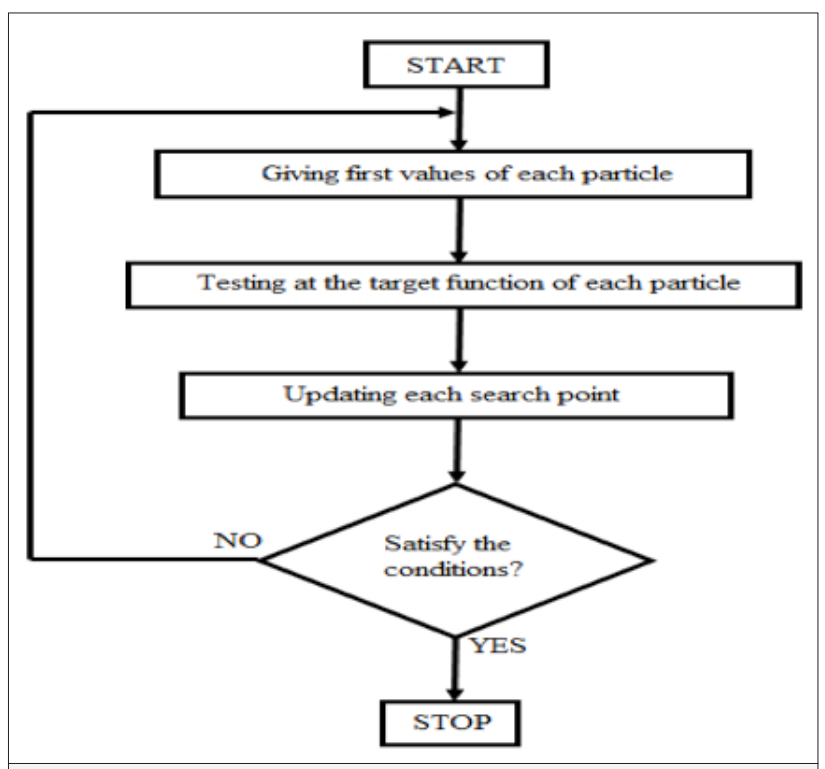

Figure 12. PSO Algorithm [15] all membership functions are arranged in sensitive intervals according to the response of the system to the control response. Fuzzy logic rules and membership functions for determining $\mathrm{PI}$ control gain ranges are obtained according to the unit step response of the system.

The fuzzy logic control algorithm is the most important factor in the errors and derivative of errors.To operate a control system at the desired level, the range of the error and the derivative of the error must be adjusted precisely. The variance of the error and derivation of error for the gas turbine is shown in Figure 14 [7].
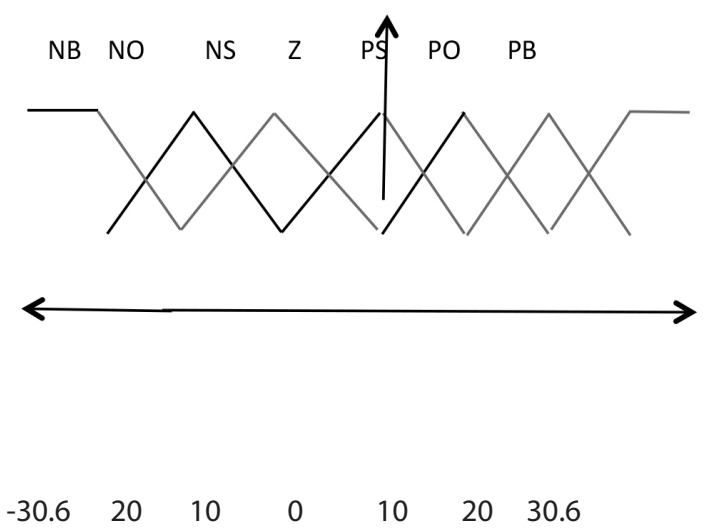

(a)

$e_{1}$

NB NO NS $Z$ PS PO PB

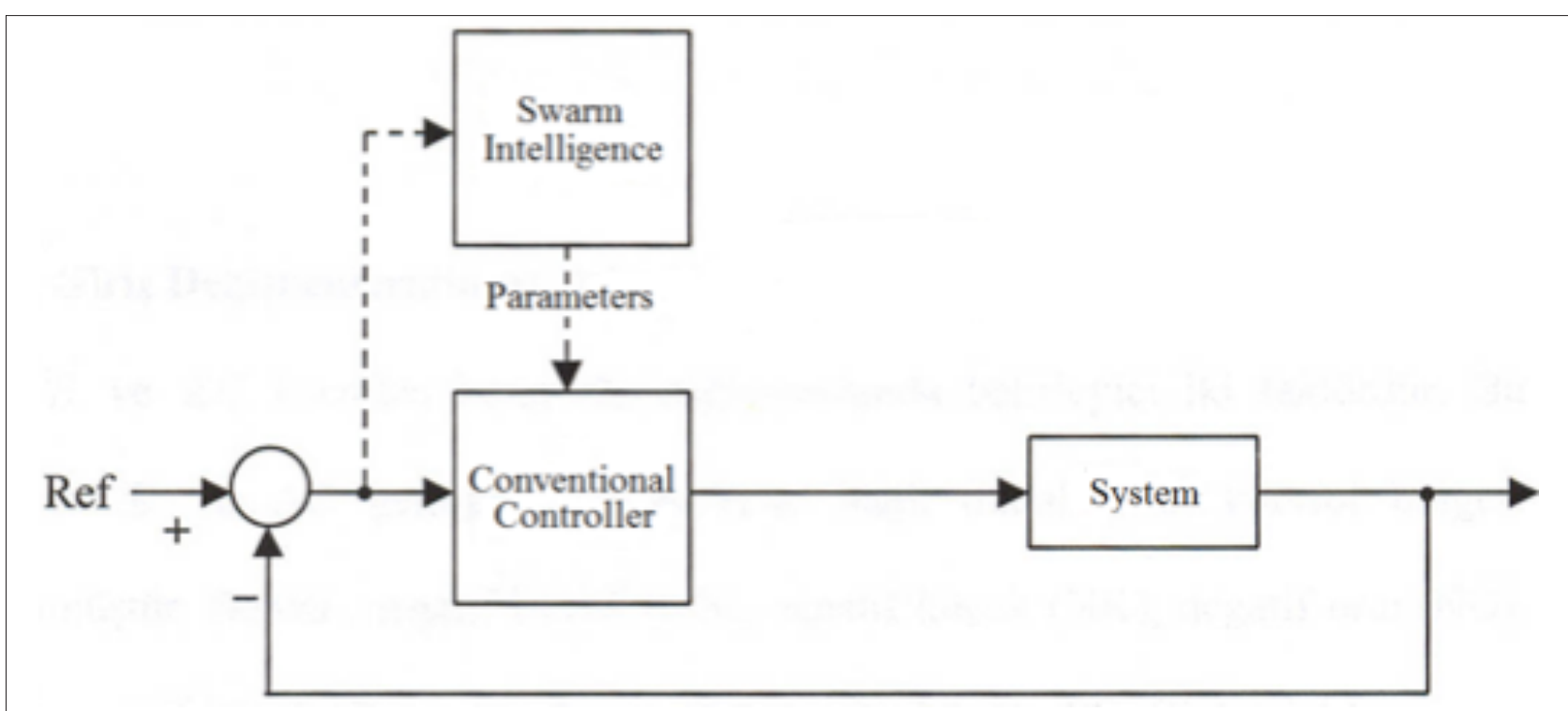

Figure 13. Block Diagram of Particle Swarm Optimization 


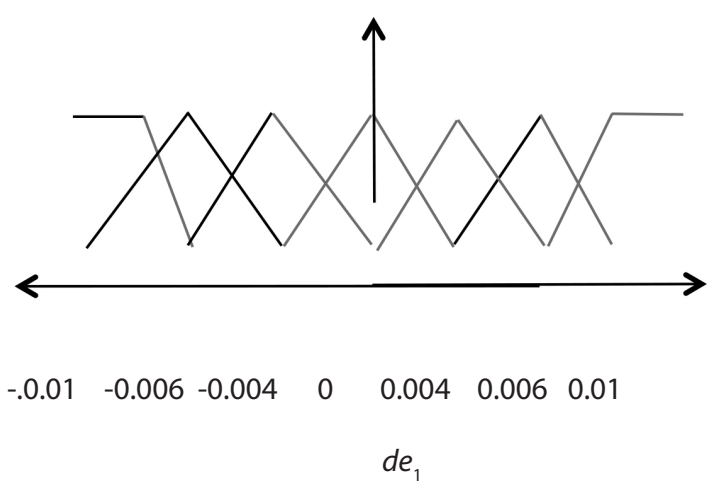

(b)

Figure 14. a, b. Ranges of Input Variables. Error (a), Derivation of Error (b)

Here, $e_{1}$ expresses the error value of the system. The error values are set to -30.6 to 30.6. de represents the derivative of the error which varies from -0.01 to 0.01 .

Proposed control system gain values $K_{p}$ and $K_{i}$ regulate the Gas Turbine by the selected PI parameters of the controller. The control gain ranges are also precisely arranged. The defuzzification rules of this system are given in Table 4 and Table 5.

The membership functions for fuzzification of the output values of the gas turbine are shown in Figure 15.a and 15.b.

Table 4: Rules of $K_{p}$ parameters for power output [7]

\begin{tabular}{lccccccc}
\hline de e & NB & NM & NS & $\mathbf{Z}$ & PS & PM & PB \\
\hline NB & $P B$ & $P B$ & $P B$ & $P B$ & $P B$ & $P M$ & $P M$ \\
\hline NM & $P M$ & $P M$ & $P M$ & $P M$ & $P M$ & $P S$ & $P S$ \\
\hline NS & $P S$ & $P S$ & $P S$ & $P S$ & $P S$ & $Z$ & $Z$ \\
\hline$Z$ & $Z$ & $Z$ & $Z$ & $Z$ & $Z$ & $N S$ & $N S$ \\
\hline PS & $N S$ & $N S$ & $N S$ & $N S$ & $N S$ & $N M$ & $N M$ \\
\hline PM & $N M$ & $N M$ & $N M$ & $N M$ & $N M$ & $N M$ & $N B$ \\
\hline PB & $N B$ & $N B$ & $N B$ & $N B$ & $N B$ & $N B$ & $N B$ \\
\hline
\end{tabular}

Table 5: Rules of $K_{i}$ parameters for power output [7]

\begin{tabular}{lccccccc}
\hline de e & NB & NM & NS & $\mathbf{Z}$ & PS & PM & PB \\
\hline NB & $N B$ & $N B$ & $N B$ & $N B$ & $N B$ & $N M$ & $N M$ \\
\hline NM & $N M$ & $N M$ & $N M$ & $N M$ & $N M$ & $N S$ & $N S$ \\
\hline NS & $N S$ & $N S$ & $N S$ & $N S$ & $N S$ & $Z$ & $Z$ \\
\hline$Z$ & $Z$ & $Z$ & $Z$ & $Z$ & $Z$ & $P S$ & $P S$ \\
\hline PS & $P S$ & $P S$ & $P S$ & $P S$ & $P S$ & $P M$ & $P M$ \\
\hline PM & $P M$ & $P M$ & $P M$ & $P M$ & $P M$ & $P M$ & $P B$ \\
\hline PB & $P B$ & $P B$ & $P B$ & $P B$ & $P B$ & $P B$ & $P B$ \\
\hline
\end{tabular}

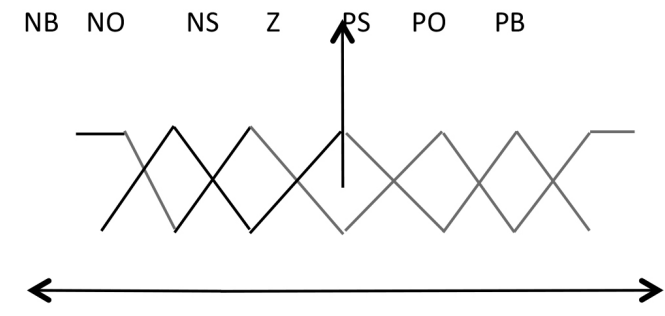

$\begin{array}{lllll}0.3463 & 0.5 & 0.64 & 0.8 & 0.9463\end{array}$

(a)

NB NO NS $Z$ PS PO PB

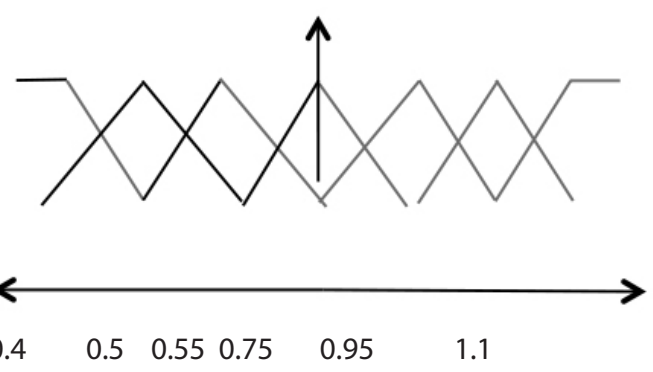

(b)

Figure 15. a, b. Ranges of Output Variables

a) $K_{p}$ b) $K_{i}$

$K_{p}$ range of the designed Gas Turbine is [0.3463 0.9463] where $K_{i}$ are designed as [0.4 1.1].

\section{Simulation and Results}

In this study, the design of PI, PSO-PI and FGPI controllers are employed. These controllers are applied into the Gas Turbine Power Plant which reduced the mathematical model. The set values of the power plant are used to in the comparison of the results. Response curves obtained from all proposed controllers are shown in Figure 16. The set value is $1 \mathrm{MW}$ and the period is 200 second as a square wave which is suitable to compare the results.

If we focus on the graph, Figure 17 and Figure 18 will be obtained.

The overshoot and settling time are presemnted in Table 6. One can see that, there is no overshoot in Conventional PI controller, the power overshoots of FGPI and PSO controllers are \%0.1

Table 6. System performance

\begin{tabular}{lcc}
\hline & Overshoot (\%) & Settling Time (s) \\
\hline PI & - & 16 \\
\hline PSO-PI & 0.2 & 10 \\
\hline FGPI & 0.1 & 8 \\
\hline
\end{tabular}




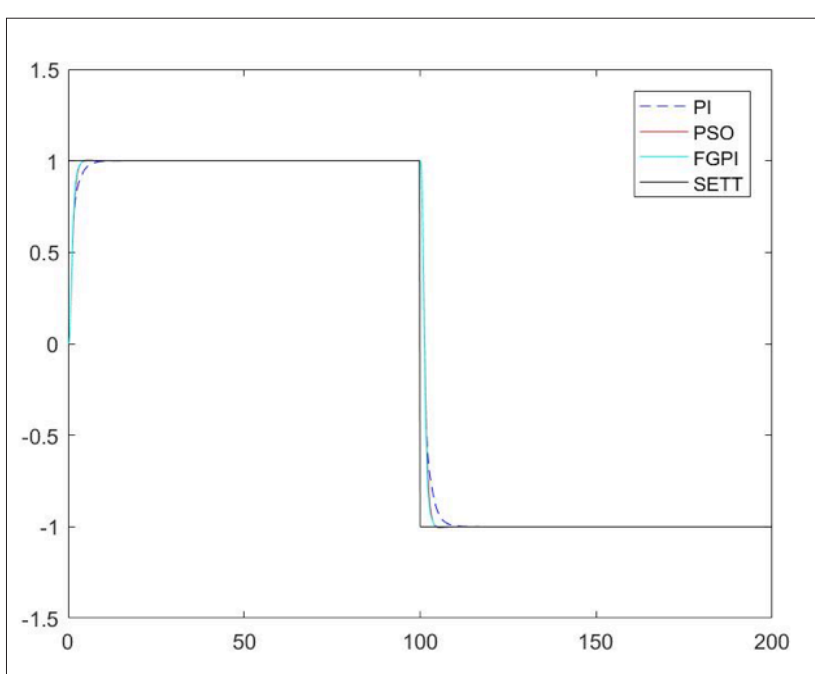

Figure 16. Power Output with All Controllers and $\% 0.2$ respectively. However, if the settling times for power output are taken into account, it will be realized that FGPI controller is less than both PI and PSO-PI controllers. According to the Figures and Table, FGPI controller is better than Conventional PI controller as well as PSO-PI controller. Since the settling time is extremely minimum to the reference signal in the Gas Turbine Power Plant.

\section{Conclusion}

In this paper, the model of Gas Turbine Power Plant in Ambarlı, Turkey is analyzed. The controller gain parameters employed in this system are obtained by conventional methods. Afterwards, three controllers namely conventional PI, PSO-PI and FGPI are proposed and compared to each other. In this comparison, minimization of the settling time is desired and it is seen that FGPI is the best among the others. Moreover, conventional PI and PSO-PI parameters reduce the performance and efficiency of

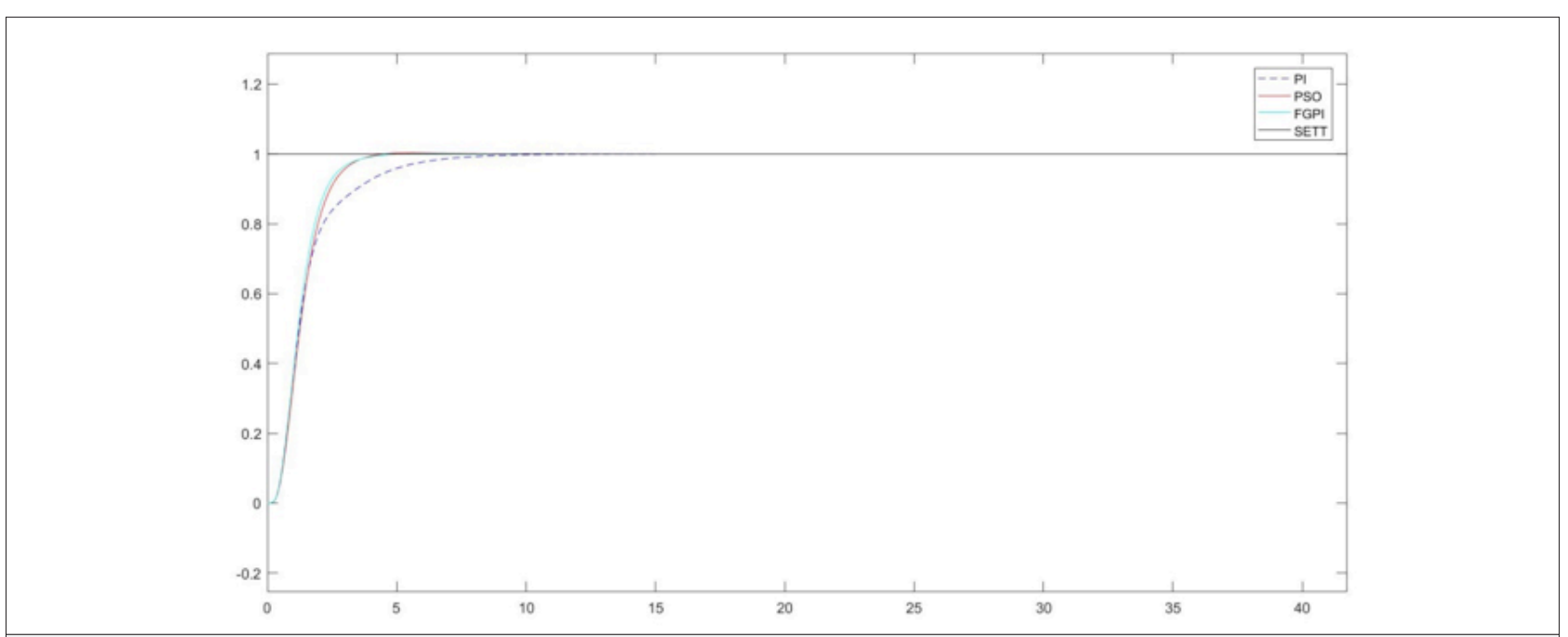

Figure 17. Rise Time Output

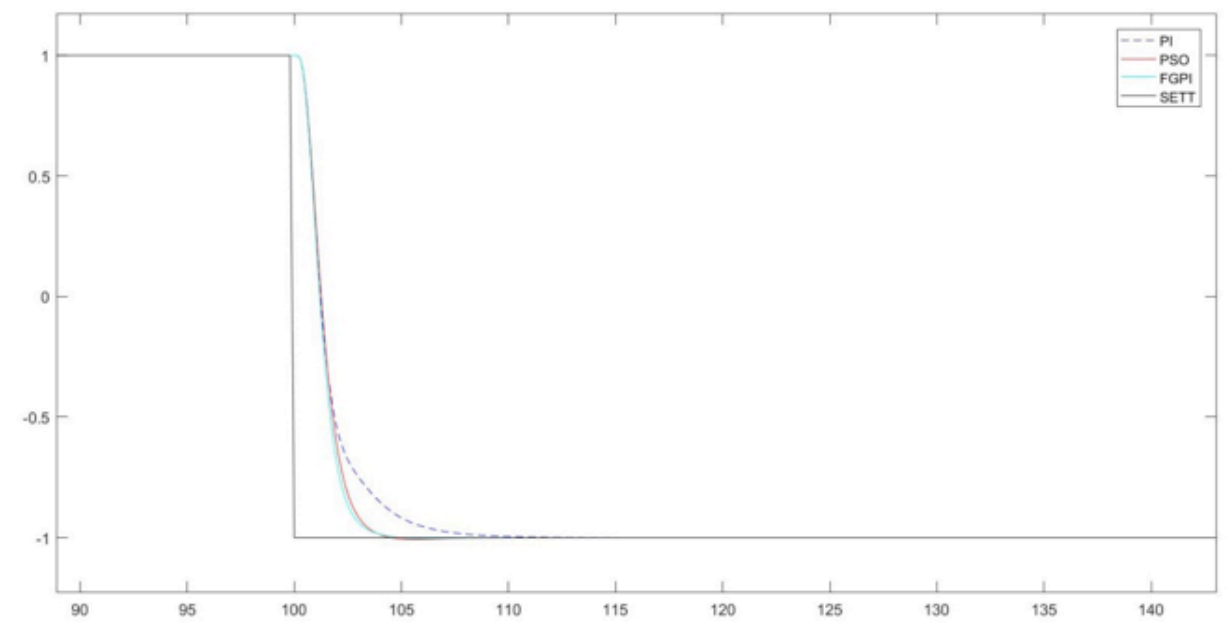

Figure 18. Fall Time Output 
the plant throughout in its service life. Consequently, it is observed that, FGPI controller achieved satisfactory performance in Gas Turbines.

Peer-review: Externally peer-reviewed.

Conflict of Interest: The authors have no conflicts of interest to declare.

Financial Disclosure: The authors declared that the study has received no financial support.

\section{References}

1. İ. Kocaarslan, E. Çam, H. Tiryaki, B. Akbıyık, "Bir Termik Elektrik Santralinde Kontrol Yönteminin Üretime Olan Etkilerinin Karşılaştırılması.,, Uluslararası 9.Yanma Sempozyumu, Kırıkkale Üniversitesi, 16-17 Kasım 2006, 402-414. (In Turkish).

2. M. A. Ehyaei, M. Tahani, P. Ahmadi, M. Esfandiari, “Optimization of fog inlet aircooling system for combined cycle power plants using genetic algorithm.", Appl Therm Eng, vol. 76, pp. 44961, 2015. [CrossRef]

3. I. Kocaarslan, E. Çam, İ. Eke, H. Tiryaki, "In a Hydroelectric Power Plant Fuzzy Logic Controller Application.,' TOK'05 Automatic Control National Meeting, Istanbul, 2-3 June 2005, 563-568. (In Turkish)

4. Ö.P. Akkaş, E. Çam, İ. Eke, Y. Arıkan, “New Optimization Algorithms for Application to Environmental Economic Load Dispatch in Power Systems", Electrica, vol. 18, no: 2, pp. 133-142, 2018. [CrossRef]

5. F. A. Boyaghch, H. Molaie, "Advanced exergy and environmental analyses and multi objective optimization of a real combined cycle power plant with supplementary firing using evolutionary algorithm.", Energy vol. 93, pp. 2267-2279, 2015. [CrossRef]
6. H. Tiryaki, "Application of Modern Control Methods in Load Distribution Systems", Istanbul University, Institute of Science, Doctoral Thesis, Istanbul. 2013. (In Turkish)

7. I. Kocaarslan, H. Tiryaki, "Comparison of PSO-PID and FGPI Controllers on a Thermal Power Plant" International Journal of Engineering Research and Development, Vol.5, No.2, June 2013. (In Turkish)

8. Debbah, A., Kherfane, H., "GA/PSO Robust Sliding Mode Control of Aerodynamics in Gas Turbine.," Acta Universitatis Sapientiae Electrical and Mechanical Engineering, vol. 10, pp.42-66, 2018. [CrossRef]

9. M. Montazeri-Gh , S. Jafari, M. R. Ilkhani, "Application of particle swarm optimization in gas turbine engine fuel controller gain tuning", Engineering Optimization, vol. 44, no. 2, 225-240, 2012. [CrossRef]

10. H. V. Haji, A. C. Monje, "Fractional order fuzzy-PID control of a combined cycle power plant using Particle Swarm Optimization algorithm with an improved dynamic parameters selection", Applied Soft Computing, vol. 58, pp. 256-264, 2017. [CrossRef]

11. B. Çiftkaya, "Analysis and Simulation of Gas Turbines Used in Electricity Generation", İstanbul Technical University, Institute of Science, Master Thesis, Istanbul. 2010. (In Turkish)

12. İ. Yüksel, "Automatic Control System Dynamics and Control Systems", Birsen Publisher, Bursa. 1997. (In Turkish)

13. J. Kennedy, R. Eberhant, " Particle Swarm Optimization", 9.Neural Networks, Proceeding IEEE Conference, pg. 1942-1948, 1995. [CrossRef]

14. M. Clerck, "The swarm and the queen: towards a deterministic and adaptive particle swarm optimization", Proceedings of the Conference on Evolutionary Computation, pp. 1951-1957, 1999. [CrossRef]

15. E. Bal, "Power Systems in Strain Control Stable Crimp Applies and Alternatives", İstanbul University, Institute of Science, Master Thesis, İstanbul. 2012. (In Turkish) 


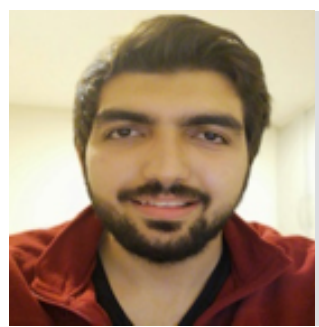

Yılmaz ARIKUŞU was born in Mersin in 1992. He received his B.Sc degree in Electrical and Electronic Engineering from Isık University in 2015. He completed his M.Sc. degree in Electrical and Electronics Engineering from Istanbul Bilgi University in 2018. Currently, he is Ph.D candidate in Electrical and Electronics Engineering at Istanbul University-Cerrahpasa. His research interests are automatic control systems, control systems design, robust control, fuzzy logic control

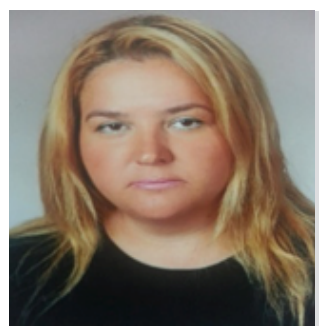

Nevra BAYHAN was born in Istanbul. She received her B.Sc. and M.Sc. degrees in Electrical and Electronics Engineering from Istanbul University in 1997 and 2001, respectively. She completed her Ph.D. in Control and Automation Engineering at Istanbul Technical University in 2008. Since 2011, she has been working at the Electrical and Electronics Engineering Department of Istanbul University - Cerrahpasa as an Assistant Professor. Her research interests are automatic control systems, control systems design, robust control, time-delay systems, digital control systems, energy, low order controller design and control of systems with parameter

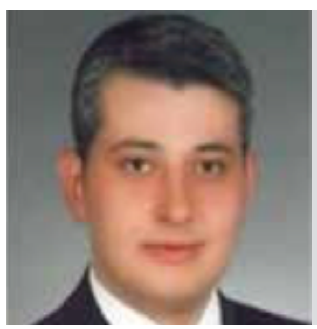

Hasan TIRYAKI was born in Denizli in 1980. He received his B.Sc. and M.Sc. degrees in Electrical and Electronics Engineering from Kirikkale University in 2002 and 2005, respectively. He received his Ph. D. degree in Electrical and Electronics Engineering from Istanbul University in 2013.Since 2016, he has been working in Electrical and Electronics Engineering Department at Istanbul University - Cerrahpasa Engineering Faculty as a Asst. Prof. His research interests are electrical cars, control systems, automation, renewable energy, power generation, transmission and distribution. 